\title{
Successful endonasal dacryocystorhinostomy in a patient with Wegener's granulomatosis
}

This article was published in the following Dove Press journal:

Clinical Ophthalmology

17 November 2009

Number of times this article has been viewed

\section{P Eloy \\ E Leruth \\ B Bertrand \\ Ph Rombaux \\ ENT and HNS department, Cliniques Universitaires de Mont-Godinne, Université Catholique de Louvain, 5530, Yvoir, Belgium}

Correspondence: Philippe Eloy HNS and ENT department, Cliniques Universitaires de Mont-Godinne, Université Catholique de Louvain, 5530 , Yvoir, Belgium Fax +32 8I 423703

Email philippe.eloy@uclouvain.be

\begin{abstract}
Wegener's granulomatosis (WG) is one form of idiopathic autoimmune vasculitis. The disease has a predilection for the upper and lower respiratory tracts (lungs, nose, sinus), and kidneys. WG may be systemic, severe, and potentially lethal, but it may also be limited to the otolaryngological area or to the eyes and the orbits. Obstruction of the lacrimal pathway is a possible complication of the disease that affects approximately $7 \%$ of patients with WG. It usually occurs as a direct extension of sinonasal disease and typically is a late manifestation. Management of such a condition is generally viewed as difficult. We report the case of a patient with a quiescent WG limited to the otolaryngological area. This patient presented a bilateral obstruction of the nasolacrimal ducts caused by bilateral extensive adhesions in the nasal cavity. Because she had several episodes of left-side acute dacryocystitis which necessitated several courses of broad-spectrum antibiotics, she successfully underwent an endonasal endoscopic dacryocystorhinostomy using a diode laser and powered instrumentation. The authors describe the clinical case, the surgical technique, and review the literature.
\end{abstract}

Keywords: Wegener's granulomatosis, recurrent dacryocystitis, endonasal DCR, diode, laser, powered instrumentation

\section{Introduction}

Wegener's granulomatosis (WG) is a rare chronic autoimmune disease characterized by the triad of small vessel necrotizing vasculitis, "geographic" necrosis and granulomatous inflammation. ${ }^{1}$ Although it can involve any organ system (eyes, heart, skin, joints, nervous system), WG mainly affects the upper and lower respiratory tracts (nose, sinus, ears, trachea, and lungs) and kidneys. ${ }^{1-4}$ The degree of organ involvement is highly variable. WG may be limited to a single organ (typically the lungs or upper respiratory tract). ${ }^{5} \mathrm{WG}$ affects men and women equally. The average age of onset is 50 years, but it can occur at almost any age. The etiology is unknown.

At the onset of the disease, the clinical presentation is nonspecific and can vary. As the disease progresses, the history becomes more typical and patients develop the classic clinical triad of sinusitis-pulmonary symptoms-renal insufficiency.

The definitive diagnosis of $\mathrm{WG}$ usually requires a combined assessment of the patient's health history (symptoms), blood and urine tests, imaging, and tissue biopsy. ${ }^{2-4}$

The presence of antineutrophil cytoplasmic antibodies (ANCAs) that react with the enzyme proteinase 3 (c-ANCAs) in neutrophils is relatively specific for WG. Their determination can help to confirm the diagnosis. Nevertheless, positive ANCAs are not conclusive and negative ANCAs are not sufficient to reject the diagnosis. c-ANCA

submit your manuscript | www.dovepress.con 
titers parallel disease activity and rising titers may herald relapse of disease. Perinuclear-staining ANCAs (p-ANCA) are seen in a wide variety of vasculitis and are of much lower clinical utility. ${ }^{5,6}$

The very early presence of red blood cells and casts can hint at a glomerulonephritis which can evolve into renal insufficiency. When clinical and serologic findings are inconclusive, tissue biopsy is necessary.

However, a pathological diagnosis can be very difficult to establish because all the characteristic diagnostic findings (necrosis, vasulitis, and granulomas) are rarely present together. Indeed, Devaney and colleagues reported that vasculitis, necrosis, and granulomatous inflammation together were seen in only $16 \%$ of all head and neck biopsy specimens. Both vasculitis and granulomatous inflammation were seen in $21 \%$ and vasculitis and necrosis in $23 \%$ of the biopsy specimens reviewed. ${ }^{7}$ Raynaud and colleagues found that head and neck biopsies usually have a low diagnostic value in WG. ${ }^{8,9}$ Ninety percent of nasal systematic biopsies performed under local anesthetic are nonspecific. For Del Buono ${ }^{10}$ and Maguchi, ${ }^{11}$ nasal biopsy is relevant for the diagnosis in only $50 \%$ of patients. To be more contributive, the biopsy must be large and targeted on macroscopic lesions. When there is no lesion, samples from paranasal sinuses obtained under general anesthetic have the highest diagnostic value in the head and neck region. ${ }^{8}$

A multidisciplinary approach should be used to treat this multisystem disease. ${ }^{4,12}$ Treatment involves the use of various regimens of corticosteroids and immunosuppressive medication. Mortality due to WG has been significantly decreased by this therapy but a significant rate of relapse and profound disease- and/or treatment-related morbidity still occur. ${ }^{1,3,4,9}$

The authors report the case of a patient with recurrent acute dacryocystitis and a quiescent WG limited to the otolaryngological area successfully treated with an endonasal endoscopic dacryocystorhinostomy.

\section{Case report}

A 35-year-old woman was referred to the Ear-Nose-Throat (ENT) department for lacrimal surgery. Figure 1A shows the preoperative view of the patient with a saddle-nose deformity and a dacryocystocele. For two years, she had been experiencing bilateral epiphora. Her left-sided epiphora was associated with recurrent episodes of acute dacryocystitis. These episodes necessitated repetitive administrations of broad-spectrum antibiotics. Her episodes became more painful over time and the last was complicated by a dacryocele. The clinical signs did not disappear with medical treatment (oral broad-spectrum antibiotics: amoxycyline plus clavulanic acid $875 \mathrm{mg}$ three times daily and topical antibiotic eyedrops). A micropuncture was performed in order to relief the pain. A culture did not grow any bacteria. After a couple of days, the pain decreased but unfortunately the dacryocele and epiphora persisted. A dacryoscan was performed. It confirmed that the lacrimal problem was caused by a nasolacrimal duct obstruction. Figures 1C and 1D show two coronal views of a dacryoscan. The lacrimal obstruction was caused by extensive adhesions developed between the nasal septum and the inferior meatus. The decision was then to perform a dacryocystorhinostomy under general anesthesia taking into consideration the patient's health history and her modified nasal anatomy.

The patient had a known history of Wegener's granulomatosis. Figures $1 \mathrm{~A}$ and $1 \mathrm{~B}$ show the changes of the nasal anatomy due to the vasculitis. The disease started in 1997 with otolaryngological manifestations that included recurrent otitis media, rhinitis, and recurrent infections. After several relapses, the disease became stable and quiescent. Since 2005 , the patient had been taking Ledertrexate (methotrexate; $6 \times 2.5 \mathrm{mg} / 1 \times /$ week). As consequences of the vasculitis, the patient ended up with a saddle nose deformity without any septal perforation, extensive adhesions in both nasal cavities and subglottic stenosis. The patient underwent surgery for the synechiae in 2004 at another hospital but unfortunately the synechiae recurred in the early postoperative period. The synechiae reduced the nasal airflow (as shown in Figure 1B) and caused bilateral obstruction of the nasolacrimal duct. The patient had subglottic stenosis and her airway diameter was reduced to $40 \%$. Fortunately the stenosis was stable and had not become worse for four years. The patient did not have signs of renal nor pulmonary insufficiency. ANCAs titers were negative.

The nasal endoscopy confirmed the extent of the adhesions and the absence of a nasal septum perforation. After discussing the issues with the patient, a dacryocystorhinostomy was performed on the left side only under general anesthesia using a laryngeal mask rather than a conventional endotracheal tube to minimize the risk of reactivation of the subglottic stenosis. An endonasal approach was performed using rigid telescopes, diode laser, and powered instrumentation. Prior to surgery, the patient had been counseled about the possibility of switching to an external approach during surgery if necessary.

The nasal cavity was prepared by placing some neurosurgical pledgets soaked with a potent decongestant (xylocaine $5 \%$ plus naphazoline) for 15 minutes before the surgery. 


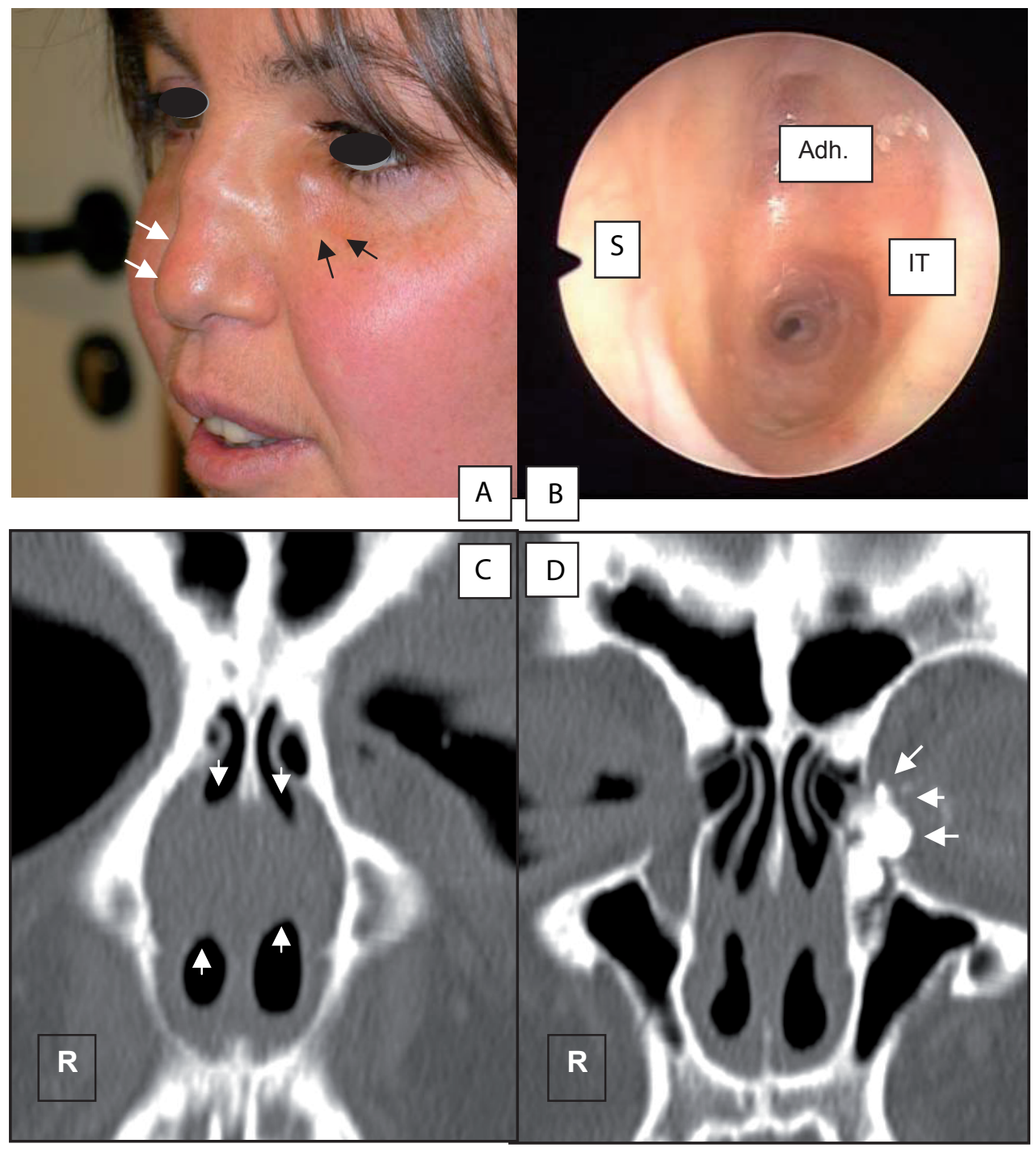

Figure I A) Preoperative view of the patient showing a dacryocele (black arrows) and a saddle-nose deformity (white arrows), consequences of a Wegener's granulomatosis. B) Nasal endoscopy of the left nasal cavity. Extensive adhesions developed between the nasal septum and the inferior turbinate reducing dramatically the diameter of the nasal cavity. C) Preoperative sinus CT scan showing bilateral extensive adhesions in the nose (white arrows). D) Preoperative dacryoscan showing an opacification of all the lacrimal outflow system (white arrows).

Abbreviations: Adh, adhesions; CT, computed tomography; IT, inferior turbinate; S, nasal septum.

The adhesions were then cut under endoscopic guidance $\left(30^{\circ}-4 \mathrm{~mm}\right.$ Hopkins rigid telescope) using the diode laser (6030 - laser fiber diameter: 600 microns; Lumenis, Yokneam, Israel). Then the entire lacrimal duct was exposed by drilling the posterior aspect of the frontal process of the maxilla with a dedicated protected drill (XPS - $2.9 \mathrm{~mm}$ angulated diamond drill for dacryocystorhinostomy; Medtronic, Minneapolis, MN, USA). The mucosa of the lacrimal pathway was incised with a sickle knife and pus was expressed. The surgical opening was located superior to the adhesions. At the end of surgery, a bicanalicular silicone tubing and silastic splint were left in place in the left nasal fossa for six weeks. Culture did not yield bacteria. Histolopathological examination of the biopsies taken during the surgery did not show any sign of active WG. During the early postoperative period, the dosage of the immunosuppressive treatment was increased for three weeks in order to avoid any possible rebound of the vasculitis.

The patient was free of ophthalmological symptoms on the left side six months after the procedure. Figure 2 illustrates the postoperative result. The dacryocele disappeared and the patient did not experience any new episode of infection (Figure 2A). The laryngeal stenosis was stable and did not need any further surgery such as tracheotomy or laser surgery. A postoperative dacryoscan confirmed the patency of the surgical opening (Figures 2C and 2D). 
The adhesions recurred slightly but the nasal patency was still better than the one observed preoperatively (Figure 2B).

\section{Discussion}

In its classic presentation, $\mathrm{WG}$ is a multiorgan systemic vasculitis but the disease may be limited to a single organ, eg, the upper respiratory tract. ${ }^{5,13}$ According to Stone, ${ }^{5}$ there are significant differences between the limited and severe forms of the disease. Indeed, patients with limited disease are nearly a decade younger at disease onset compared with patients with severe disease. $58 \%$ of patients with limited WG are women. Patients with limited disease tend to have longer disease duration, a greater likelihood of experiencing exacerbation of previous disease following a period of remission and a higher prevalence of destructive upper respiratory tract disorders at the time of enrollment (eg, saddle-nose deformity). In such a limited form, ANCA titers are usually negative. ${ }^{5,6}$ Our case illustrates all these data perfectly well.

Otolaryngological manifestations are very common in WG, affecting more than $80 \%$ of the patients. ${ }^{13-15}$ These manifestations can either be the initials signs of the disease and/or the only ones. Therefore, clinicians should have a high index of suspicion when the patient has a long-lasting history of unspecific symptoms, such as chronic nasal pain, stuffiness, nosebleeds, chronic discolored rhinorhea, rhinitis, long-lasting crusting, saddle-nose deformity, septal perforation, and extensive adhesions. Subglottic stenosis may be another consequence of the disease causing hoarseness, shortness of breath, or cough. ${ }^{14-18}$ Blockage of the Eustachian tube can lead to a conductive hearing loss.

Ophthalmologic manifestations are also common in WG and may be the presenting feature..$^{5-7,19-21}$ They range from mild conjunctivitis and episcleritis to more

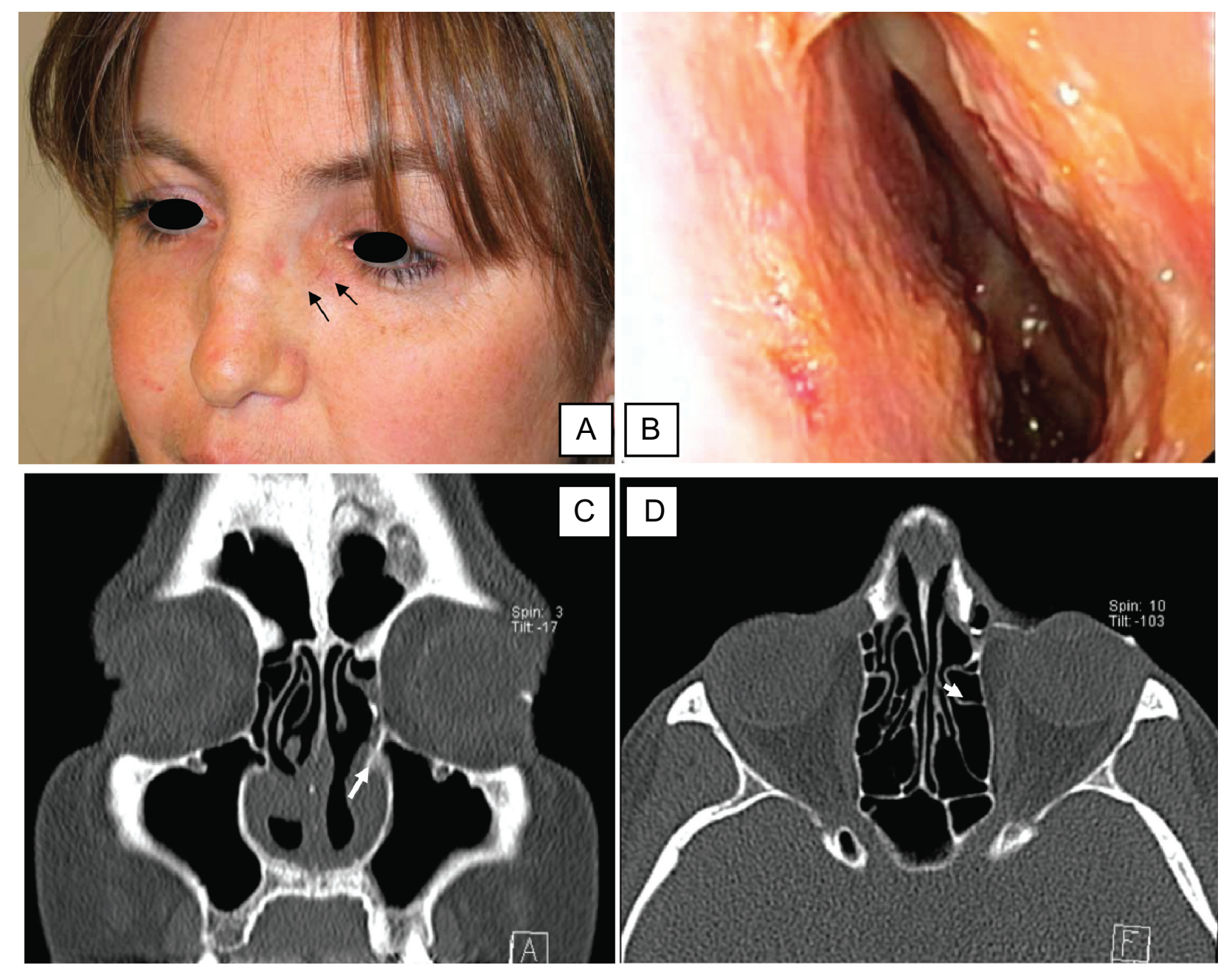

Figure 2 A) Postoperative view of the patient confirming the disappearance of the dacryocele (black arrows). B) Postoperative endoscopy of the left nasal cavity showing the absence of recurrence of the adhesions posteriorly. $\mathbf{C}$ and $\mathbf{D}$ ) Postoperative dacryoscan confirming the patency of the surgical opening on the left side: presence of medium contrast in the nasal cavity (white arrow). 
severe inflammation with keratitis, scleritis, uveitis, and retinal vasculitis. They usually respond well to systemic antiinflammatory and immunosuppressive agents rather than to a topical medical treatment. Involvement of orbital tissues can lead to double vision, decrease in vision, or even blindness. These complications require immediate medical attention. Orbital decompression may be indicated.

Involvement of the lacrimal pathway can be another issue of the disease, affecting approximately $7 \%$ of the patients. This can be caused by a granulomatous inflammation of the paranasal sinus but is more commonly the consequence of adhesions blocking the nasolacrimal duct. This usually occurs as a late manifestation. Our clinical case illustrates such a complication. The patient may complain of epiphora, sometimes in conjunction with recurrent infections (dacryocystitis). The former is usually better tolerated than the latter which commonly leads to surgery.

Lacrimal surgery in WG is considered difficult and often has poor outcomes. ${ }^{22,23}$ Currently, lacrimal surgery is not recommended when the disease (WG) is active because the risks of recurrence or extension of the granulomatosis to the lacrimal sac, orbit and the skin are high. ${ }^{23,24}$ Lacrimal surgery can be performed in two different ways: dacryocystorhinostomy or dacryocystectomy. Dacryocystorhinostomy consists of diverting the lacrimal flow into the nasal cavity via a stoma created in front of the attachment of the middle turbinate to the lateral nasal wall. This is usually the first surgical option recommended. Dacryocystorhinostomy can be performed via an external or an endonasal approach.

The external approach is the most commonly performed, usually by an ophthalmologist. ${ }^{22-24}$ This approach is the gold standard for the treatment of nasolacrimal duct obstruction. The advantage of this approach is the ability to create a wide stoma, located high into the nose without any consideration of the nasal anatomy. In experienced hands and inactive $\mathrm{WG}$, the success rate is high. Rose reported excellent results $(13 / 14)$ in a series of 14 patients without significant morbidity. ${ }^{22}$ Good results have also been reported by Hartwig ${ }^{23}$ and Glatt. ${ }^{25}$ Nevertheless other authors have reported poor outcomes characterized by recurrence, wound necrosis, and development of nasocutaneous fistula. ${ }^{23,25-27}$

Dacryocystorhinostomy can also be performed using an endonasal approach. With the development of the endonasal endoscopic surgery, endonasal dacryocystorhinostomy is increasingly performed by both ophthalmologists and ENT surgeons to treat low mechanical obstruction of the lacrimal pathway. ${ }^{27-30}$ The procedure is performed quickly, in a day clinic setting, and has a high rate of success with minimal morbidity.

Endonasal surgery can be more challenging in patients with WG. In our case, the surgery ended up being more difficult than usual and required specific instrumentation. ${ }^{30,31}$ The anatomy of the nose was altered: the adhesions were extensive and made the access to the lacrimal eminence very narrow. The adhesions were cut and vaporized with the diode laser (Lumenis 6030). This type of surgical laser system is better than the $\mathrm{CO}_{2}$ laser in endonasal surgery. The laser energy is delivered through an optic fiber and is focused at the tip of the fiber. This reduces the risk of burning the skin or the alar cartilages. This laser surgical system also provides excellent hemostasis because the laser energy is absorbed by blood..$^{32,33}$ It can also cut and vaporize the soft tissue, particularly adhesions. Unfortunately, lysis of adhesions created significant blood oozing. This made frequent cleaning of the tip of the lens necessary, thus making the procedure a little bit longer than usual. In our case, because of the adhesions, the stoma was created high in the nasal cavity to lower the risk of recurrence. The stoma was located superior to the adhesions, at the level of the root of the middle turbinate. The technique we used was described previously. ${ }^{30}$ We used powered instrumentation (Xomed XPS microdebrider; Medtronic) with a dedicated angulated and protected diamond drill for dacryocystorhinostomy, angulated telescope ( $30^{\circ}$ rigid telescope) and forceps. The advantages of this surgical approach and technique were to avoid a skin incision with its potential risk of necrosis, to preserve the lacrimal function by avoiding dissection of the medial canthus structures, to rehabilitate the nasal function by improving the nasal patency and to create enough space in the nose to be able to stop any possible intraoperative hemorrhage by packing. One potential disadvantage of this technique is the cost of the necessary equipment. Fortunately, many ENT surgeons have these devices within their department.

Another treatment option consists of performing a dacryocystectomy. ${ }^{27}$ This was proposed by Holds and Anderson as an alternative to dacryocystorhinostomy for dacryocystitis in patients with WG in whom epiphora was not a major concern because they had several cases of failure or complications after external dacryocystorhinostomy. We recommend reserving this procedure for revision surgery in the event of failure of either an endonasal or external dacryocystorhinostomy.

\section{Conclusion}

This case illustrates that an endonasal endoscopic dacryocystorhinostomy can be successful in a patient with WG and 
extensive adhesions provided that the stoma is created very high into the nose, superior to the adhesions. The surgery requires the use of angulated telescopes, lasers, and powered instrumentation. It must be performed when WG is quiescent by a surgeon with expertise in endonasal surgery.

\section{Disclosures}

The authors disclose no financial or commercial support that could lead to a conflict of interest.

\section{References}

1. White ES, Lynch JP. Pharmacological therapy for Wegener's granulomatosis. Drugs. 2006;66(9):1209-1228.

2. Moosig F, Lamprecht P, Gross WL. Wegener's granulomatosis: the current view. Clin Rev Allergy Immunol. 2008;35(1-2):19-21.

3. Erickson VR, Hwang PH. Wegener's granulomatosis: current trends in diagnosis and management. Curr Opin Otolaryngol Head Neck Surg. Jun 2007;15(3):170-176.

4. Khan AM, Elahi F, Hashmi SR, et al. Wegener's granulomatosis: a rare, chronic and multisystem disease. Surgeon. 2006;4(1):45-52.

5. Stone JH. Wegener's Granulomatosis Etanercept Trial Research group. Limited versus severe Wegener's granulomatosis: baseline data on patients in the Wegener's granulomatosis etanercept trial. Arthritis Rheum. 2004;50(1):334-335; author reply, 335-336.

6. Egner W, Chapel HM. Titration of antibodies against neutrophil cytoplasmic antigens is useful in monitoring disease activity in systemic vasculitis. Clin Exp Immunol. 1990;82(2):244-249.

7. Devaney KO, Travis WD, Hoffman G, et al. Interpretation of head and neck biopsies in Wegener's granulomatosis. A pathologic study of 126 biopsies in 70 patients. Am J Surg Pathol. 1990;14(6): 555-564.

8. Raynaud P, Garrel R, Rigau V, et al. How can the diagnostic value of head and neck biopsies be increased in Wegener's granulomatosis: a clinicopathologic study of 49 biopsies in 21 patients. Ann Pathol. 2005;25(2):87-93.

9. Yi ES, Colby TV. Wegener's granulomatosis. Semin Diagn Pathol. 2001;18(1):34-46.

10. Del Buono EA, Flint A. Diagnostic usefulness of nasal biopsy in Wegener's granulomatosis. Hum Pathol. 1991;22(2):107-110.

11. Maguchi S, Fukuda S, Takizawa M. Histological findings in biopsies from patients with cytoplasmic-antineutrophil cytoplasmic-antibody (cANCA)-positive Wegener's granulomatosis. Auris Nasus Larynx. 2001;28(Suppl):S53-S58.

12. Reinhold-Keller E, Beuge N, Latza U, et al. An interdisciplinary approach to the care of patients with Wegener's granulomatosis: long-term outcome in 155 patients. Arthritis Rheum. 2000;43(5):1021-1032. Erratum in: Arthritis Rheum. 2000;43(10):2379.

13. Cannady SB, Batra PS, Koening C, et al. Sinonasal Wegener's granulomatosis: a single-institution experience with 120 cases. Laryngoscope. 2009;119(4):757-761.
14. Gottschlich S, Ambrosch P, Kramkowski D, et al. Head and neck manifestations of Wegener's granulomatosis. Rhinology. 2006;44(4):227-233

15. Cadoni G, Prelajade D, Campobasso E, et al. Wegener's granulomatosis: a challenging disease for otolaryngologists. Acta Otolaryngol. 2005;125(10):1105-1110.

16. Solans-Laqué R, Bosch-Gil J, Canela M, et al. Clinical features and therapeutic management of subglottic stenosis in patients with Wegener's granulomatosis. Lupus. 2008;17(9):832-836.

17. Blaivas AJ, Strauss W, Yudd M. Subglottic stenosis as a complication of Wegener's granulomatosis. Prim Care Respir J. 2008;17(2):114-116.

18. Mahajan R, Gupta R, Sharma A. Wegener's granulomatosis and subglottic stenosis: how to handle the airway? Acta Anaesthesiol Scand. 2009;53(3):412-413.

19. Fechner FP, Faquin WC, Pilch BZ. Wegener's granulomatosis of the orbit: a clinicopathological study of 15 patients. Laryngocope. 2002;112(11):1945-1950.

20. Harper SL, Letko E, Samson CM, et al. Wegener's granulomatosis: the relationship between ocular and systemic disease. J Rheumatol. 2001;28(5):1025-1032.

21. Pakrou N, Selva D, Leibovitch I. Wegener's granulomatosis: ophthalmic manifestations and management. Semin Arthritis Rheum. 2006;35(5):284-292.

22. Kwan AS, Rose GE. Lacrimal drainage surgery in Wegener's granulomatosis. Br J Ophthalmol. 2000;84(3):329-331.

23. Hardwig PW, Bartley GB, Garrity JA. Surgical management of nasolacrimal duct obstruction in patients with Wegener's granulomatosis. Ophthalmology. 1992;99(1):133-139.

24. Kwan AS, Rose GE. Orbital Wegener's granuloma resulting from direct extension of nasal disease through a surgical rhinostomy. $\mathrm{Br} \mathrm{J}$ Ophthalmol. 1998;82(2):198.

25. Glatt HJ, Putterman AM. Dacryocystorhinostomy in Wegener's granulomatosis. Ophthal Plast Reconstr Surg. 1990;6(3):207-210.

26. Jordan DR, Miller D, Anderson RL. Wound necrosis following dacryocystorhinostomy in patients with Wegener's granulomatosis. Ophthalmic Surg. 1987;18(11):800-803.

27. Holds JB, Anderson RL, Wolin MJ. Dacryocystectomy for the treatment of dacryocystitis patients with Wegener's granulomatosis. Ophthalmic Surg. 1989;20(6):443-444.

28. Woog JJ, Kennedy RH, Custer PL, et al. Endonasal dacryocystorhinostomy: a report by the American Academy of Ophthalmology. Ophthalmology. 2001;108(12):2369-2377.

29. Watkins LM, Janfaza P, Rubin PA. The evolution of endonasal dacryocystorhinostomy. Surv Ophthalmol. 2003;48(1):73-84.

30. Wormald PJ. Powered endonasal dacryocystorhinostomy. Laryngoscope. 2002;112(1):69-72.

31. Wong RJ, Gliklich RE, Rubin PA, et al. Bilateral nasolacrimal duct obstruction managed with endoscopic techniques. Arch Otolaryngol Head Neck Surg. 1998;124(6):703-706.

32. Newman J, Anand V. Applications of the diode laser in otolaryngology. Ear Nose Throat J. 2002;81(12):850-851.

33. Sroka R, Janda P, Killian T, et al. Comparison of long term results after Ho: YAG and diode laser treatment of hyperplastic inferior nasal turbinates. Lasers Surg Med. 2007;39(4):324-331.
Clinical Ophthalmology

\section{Publish your work in this journal}

Clinical Ophthalmology is an international, peer-reviewed journal covering all subspecialties within ophthalmology. Key topics include: Optometry; Visual science; Pharmacology and drug therapy in eye diseases; Basic Sciences; Primary and Secondary eye care; Patient Safety and Quality of Care Improvements. This journal is indexed on Submit your manuscript here: http://www.dovepress.com/clinical-ophthalmology-journal
Dovepress

PubMed Central and CAS, and is the official journal of The Society of Clinical Ophthalmology (SCO). The manuscript management system is completely online and includes a very quick and fair peer-review system, which is all easy to use. Visit http://www.dovepress.com/ testimonials.php to read real quotes from published authors. 